\title{
Overuse injuries in the athlete
}

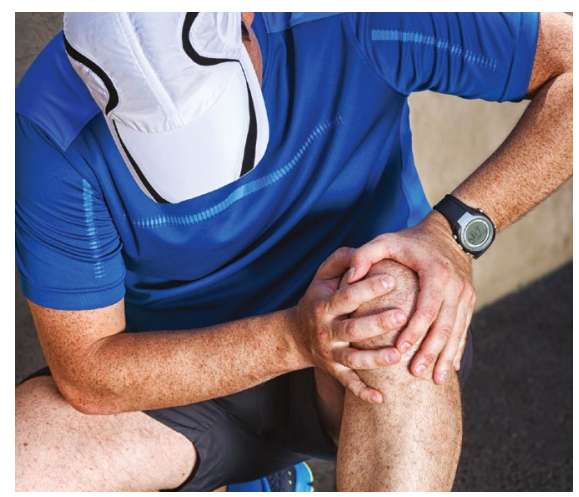

CPD

Kieran Fallon

\section{Background}

Most general practices will have patients who have more than a passing interest in fitness and exercise. These range from the elite athlete to the recreational enthusiast. These patients are highly motivated, but treating them can be challenging.

\section{Objective}

The aims of this article are to increase awareness of the management of a number of overuse injuries frequently seen in athletes, to assist in understanding the mindset of the athlete in relation to his or her injuries and to indicate the importance of a confident approach to these problems and a multidisciplinary management plan in facilitating a successful outcome.

\section{Discussion}

Athletes generally have dynamic personalities and high standards for themselves and others. Complete rest can be anathema to them. Fortunately, in cases of tendinopathy, a structured exercise program is an important component of management. A proactive approach, often with the assistance of a physiotherapist, is likely to improve outcomes.
THE AUSTRALian Oxford Dictionary defines an athlete as 'a skilled performer in physical exercises'. ${ }^{1}$ Other references indicate that participation in competition should be included in the definition. The boundaries of this definition are unclear, but inclusive coverage stretches from world champions through to the recreational athlete who is interested in improving or maintaining his or her physical performance.

To facilitate a successful medical interaction, the mindset of the athlete needs to be understood. High-performing athletes, and often recreational athletes, tend to have the following characteristics: high levels of motivation and confidence, an inner drive to succeed, self-discipline, a strong sense of focus, high resilience and perfectionism. ${ }^{2}$ Both high-level and recreational athletes derive different, indeed greater, meaning from sport and exercise than non-participants. They are respectful of expertise, dislike rest and want to return to sport as soon as possible.

The definition of an overuse injury is generally based on the concept of an injury occurring in the absence of a single identifiable traumatic cause. ${ }^{3}$ Overuse is a relative term applied to conditions for which the mechanism of injury is a single or closely related action repeated many times. It has been suggested, mainly from retrospective studies, that the occurrence of overuse injury depends on many factors including the number of repetitions, age, previous injuries, state of training, individual biomechanical variation, genetics and rate of change of training load. ${ }^{4}$

However, this has been questioned by a recent prospective study of 300 runners, which indicated that flexibility, arch height, quadriceps angle, rearfoot motion, lower extremity strength, weekly mileage, footwear and previous injury are not significant aetiological factors across all overuse running injuries. ${ }^{5}$

There is very little published evidence related to presentations of overuse sporting injuries to general practitioners (GPs). When available, it generally refers to frequencies of injuries to general body regions without mention of specific diagnoses. ${ }^{6}$

\section{The lower limb}

Many overuse injuries to the lower limb of athletes affect tendons. Histological evidence indicates that in established cases, which are those generally seen in general practice, the predominant pathology is degenerative with some cellular and biochemical evidence of chronic inflammation. ${ }^{7,8}$ This has 
resulted in the change in terminology from tendinitis to tendinopathy and explains the relative ineffectiveness of anti-inflammatory treatments.

\section{Achilles tendinopathy}

Achilles tendinopathy occurs mainly in patients involved in sports requiring running or jumping. The most frequent presentation is as mid-tendon pain of gradual onset with little, or a fusiform, swelling typically 2-6 cm from the tendon's insertion into the calcaneus. Insertional tendinopathy is associated with pain and, at times, swelling at the calcaneal insertion. Provocative clinical tests used to assist in diagnosis and/or monitor progress include single leg heel raises (low load) and hopping on the affected leg (high load). ${ }^{9}$

\section{Patellar tendinopathy}

Patellar tendinopathy occurs primarily in patients undertaking sports that involve jumping, such as volleyball, basketball and netball. Pain that has a gradual onset and is aggravated by jumping and bounding is felt in the region of the lower pole of the patella at the origin of the tendon. Tenderness is felt in the same region.

Provocative clinical tests used to augment diagnosis and/or monitor progress include performing a squat with the feet on a declining surface (low load) and a high single-leg jump or landing from a height (high load). ${ }^{9}$

\section{General management principles for tendinopathy}

The management of established tendinopathy for athletes can be difficult, and some aspects remain controversial. Management is based primarily on a supervised exercise program, the exact details of which require further investigation. ${ }^{10}$

The following general principles apply to most cases of established tendinopathy. Any contradictory advice related to specific tendons is mentioned in sections of this article related to those specific tendons.
- Educate the patient about the condition, avoiding use of the term 'degenerative'. Indicate that tendons adapt to increases in training load, but often, in those keen to excel, the desire to improve can exceed the capability of the tendon. The shared goal is to rebalance the stress with the capabilities of the tendon. This will take some time and application.

- Avoid complete rest but also avoid high loads on the tendon, such as jumping, in cases of patellar or Achilles tendinopathy. Substitute isometric exercises; when tendon pain decreases, higher load can be added.

Eccentric exercise can be added when pain is controlled. ${ }^{11}$ The assistance of a physiotherapist experienced in management of tendon pathology can be very useful during the exercise/ rehabilitation phase.

- Consider alternative forms of exercise, which can maintain training adaptations such as increases in plasma volume and muscle enzyme concentrations while not overly stressing the injured tendon.

- Monitor tendon load. If pain increases, for example by $>2 / 10$ after exercise, reduce the load for several days and return to exercise at a lower level.

- Where patients are seeking relevant information, advise them that:

- stretching does not improve outcomes and may be detrimental

- nonsteroidal anti-inflammatory drugs (NSAIDs) do not change the outcome and are rarely required for pain relief ${ }^{11}$

- corticosteroid injections, although used frequently, are generally not appropriate in the early phase of treatment despite some evidence for short-term pain relief. ${ }^{12}$

- If patients inquire about newer 'biological' therapies, including platelet-rich plasma (PRP) and mesenchymal stem cells, advise them that recent systematic reviews suggest that there may be a role for PRP injection in some tendinopathies, but this issue is not resolved in the literature. ${ }^{13-16}$ There is no good evidence for the use of mesenchymal stem cells in the management of tendinopathy. ${ }^{17}$

- To prevent recurrence, assess biomechanical risk factors and training. ${ }^{18}$

- Consider carefully the need for ultrasonography or other investigation. Clinical diagnosis is often satisfactory.

- Be prepared to support the patient though a relatively prolonged course, which may be four months or longer.

- If the patient fails to respond progressively, reconsider the diagnosis, further investigation or referral to a physician in sport and exercise medicine (SEM).

\section{Iliotibial band syndrome}

Iliotibial band syndrome is the second most common running injury and the most common cause of lateral knee pain in runners. ${ }^{19}$ It is also associated with cycling, and less frequently with field sports, hockey, rowing, swimming, hiking and basketball. It is a syndrome related to friction and is not a tendinopathy. ${ }^{19}$

The iliotibial band is a long dense fibrous structure that is a lateral thickening of the fascia lata in the thigh. It also receives most of the tendon of gluteus maximus. Distally it passes over the lateral femoral epicondyle. If the leg is extended at the knee, the iliotibial band can be seen as the structure leading to flattening of the lateral aspect of the thigh.

Pain at the lateral aspect of the knee occurs as a result of pressure leading to friction of the band on the lateral femoral condyle as the knee moves through 30 degrees of flexion. The pain begins after a reasonably consistent duration of running and worsens if running continues. The athlete eventually cannot continue.

Focal tenderness will be found over the condyle, and a useful clinical test involves placing pressure over the condyle and moving the knee through 30 degrees of flexion, thereby reproducing the pain.

Management involves avoidance of aggravating activities for up to 4-6 weeks, with substitution of alternative activities to maintain current training adaptations. Ice and NSAIDs may help for acute pain. The patient should institute iliotibial 
band stretches, such as crossing the legs while standing and leaning away from the affected side, which places the iliotibial band under maximum stretch. The stretch is held for 30 seconds and repeated five times each stretch session, three times per day.

Biomechanical assessment of the lower limbs, including footwear, is generally performed by an SEM physician or physiotherapist who can also advise on other stretches and strengthening exercises. Corticosteroid injection at the level of the lateral femoral epicondyle, under the iliotibial band, can be used following failure of more conservative management. Recalcitrant cases can be referred for surgical management.

\section{Medial tibial stress syndrome: Shin splints}

Medial tibial stress syndrome is defined as exercise-induced pain along the middle to distal postero-medial aspect of the tibia. ${ }^{20}$ Earlier thought to be related to tibial periostitis caused by traction, more recent reports suggest that, while the exact aetiology is unclear, the most common causes are likely to be tibial stress reactions or stress fractures and chronic exertional compartment syndrome involving the deep posterior compartment of the lower leg. ${ }^{21,22}$

In cases of tibial stress reactions and fractures, pain along the medial bone border may be particularly related to heel strike. Initially, in the bone stress phase, the pain typically occurs at the onset of activity and disappears as the athlete warms up, only to reappear after cessation of exercise. With further overuse, pain becomes more constant during running, eventually leading to cessation of exercise. Pain at night and with any weight bearing can occur with stress fractures.

On examination, pain is felt on hopping or jumping. In cases of stress reaction, a linear area of tenderness will be found at the medial tibial border. If a stress fracture is present, the tenderness will be more focal. Diagnosis can be made on clinical features. ${ }^{23}$ Should investigations be ordered, X-ray, bone scan and magnetic resonance imaging will reveal stress fractures. Stress reactions will generally not be seen on X-ray.

Management involves a reduction in training load until pain resolves. Alternative activities such as cycling, swimming and running in deep water using a floatation device are useful for maintenance of fitness. Once the pain has resolved, a gradual return to previous training levels can occur.

Chronic exertional compartment syndrome of the deep posterior compartment can present with medial tibial pain. The pain is often described as a tightness or pressure and tends to come on at a reasonably consistent running distance. It worsens with continued running and eventually leads to cessation of running. The pain resolves with rest and elevation of the limb, often within minutes.

As the deep posterior compartment is not accessible to palpation, examination may be normal. The only definitive investigation is compartment pressure testing.

While a number of non-surgical therapeutic interventions have been suggested, none have high-level evidence to support them, with the exception of cessation of the inciting activity. ${ }^{24,25}$ If this is not acceptable, fasciotomy can be considered.

\section{The upper limb}

\section{Subacromial pain syndrome}

Subacromial pain syndrome comprises all non-traumatic, usually unilateral, shoulder problems that cause pain, localised around the acromion, often worsening during or subsequent to lifting of the arm. The different clinical and/or radiological namessuch as bursitis, supraspinatus tendinopathy, partial tear of the rotator cuff, biceps tendinitis or tendon cuff degenerationare included in the syndrome. ${ }^{26}$

Rotator cuff tendinopathy most frequently affects the supraspinatus tendon. Impingement syndrome results from mechanical impingement of the rotator cuff tendons and associated structures beneath the anteroinferior portion of the acromion, especially when the shoulder is placed in the forwardflexed and internally rotated position.

When defined as shoulder pain that interferes with training or progress in training, the incidence of swimmer's shoulder is approximately $35 \%$ in elite and senior level swimmers. ${ }^{27}$

In subacromial pain syndrome, pain is felt at the anterior or lateral aspects of the shoulder when overhead activities such a swimming or throwing are undertaken. When impingement is present, abduction will be limited, painful or both.

Clinical tests for subacromial pathologies have been assessed in four relatively recent systematic reviews and meta-analyses. ${ }^{28-31}$ Interpretation of these studies is complicated by the varying definitions of rotator cuff disease used. By including full-thickness rotator cuff tears, these studies assess beyond the definition of subacromial pain syndrome used above.

The authors of the 2013 Cochrane review indicated that 'there is insufficient evidence on which to base selection of physical tests for shoulder impingements, and local lesions of bursa, tendon or labrum that may accompany impingement, in primary care'. ${ }^{28}$ In his 2012 meta-analysis, Hegedus concluded that, in relation to subacromial impingement, the use of no single test could be unequivocally recommended but that 'the strongest summary sensitivity was for the Hawkins-Kennedy test (80\%)'. ${ }^{29}$ In 2012, Alqunaee et al reported on tests for subacromial impingement syndrome defined as 'pain and pathology relating to the subacromial bursa and rotator cuff tendons within the subacromial space'. The frequently used Hawkins-Kennedy, empty can and drop arm tests were found to have likelihood ratios of $1.79,1.81$ and 2.62 , respectively, suggesting that they should be 'interpreted with caution'. ${ }^{30}$

Finally, Hermans et al, using a definition similar to Alqunaee et al, concluded that among the pain provocation tests, a positive painful arc test result was the only finding with a positive likelihood ratio greater than 2, at 3.7. The authors also suggested that a positive drop arm test (defined in this study as a strength test), with a likelihood ratio of 3.3, might help identify patients with rotator cuff disease. ${ }^{31}$

These reviews highlight the relative inadequacy of individual tests and the difficulty in identifying specific pathologies by examination alone. 
Management of rotator cuff tendinopathy follows the general plan for tendinopathy as previously described in this article. However, for analgesia in the short term, NSAIDs are effective. ${ }^{32}$ Recent evidence indicates that subacromial corticosteroid injection is superior to no treatment ${ }^{33}$ and local anaesthetic injection $^{34}$ at up to eight weeks following the injection. Should a significant, inflamed bursa be present, a corticosteroid injection into the bursa is appropriate. A trial of physical therapy, rather than manual therapy, is supported by systematic reviews that concluded that exercise has both short- and long-term benefits with respect to pain and function in rotator cuff disease. ${ }^{35}$

In relation to surgical management, a recent Cochrane review did not support the use of subacromial decompression surgery in the treatment of rotator cuff disease manifesting as painful shoulder impingement. ${ }^{36}$

\section{Conclusion}

Knowledge of common injuries and a clear understanding of an athlete's goals are the bases for successful injury management. Combining these with a positive outlook; informed history-taking; competent examination and a structured, well-monitored, often multidisciplinary treatment plan facilitates optimal outcomes for the athlete and GP.

\section{Key points}

- Athletes often dislike complete rest but generally will comply with an active rehabilitation program.

- Tendinopathies can be difficult to treat. Their management focuses on a progressive exercise program.

- Collaboration with a physiotherapist and assessment of biomechanical predisposing factors can be highly beneficial in the management of overuse injuries.

\section{Author}

Kieran Fallon MBBS (Hons), MD (ANU), MSpExSc, MHEd, FRACGP, FACSEP, SFHEA, Professor of Musculoskeletal, Sport and Exercise Medicine,
Faculty of Medicine, College of Health and Medicine, Australian National University, ACT; Visiting Medical Officer, Department of Rheumatology, The Canberra Hospital, ACT. kieran.fallon@anu.edu.au

Competing interests: None.

Funding: None.

Provenance and peer review: Commissioned, externally peer reviewed.

\section{References}

1. Moore B. Australian Oxford Dictionary. Melbourne: Oxford University Press, 1999.

2. MacNamara Á, Button A, Collins D. The role of psychological characteristics in facilitating the pathway to elite performance Part 1: Identifying mental skills and behaviours. Sport Psychol 2010;24(1):52-73. doi: 10.1123/tsp.24.1.52.

3. Aicale R, Tarantino D, Maffulli N. Overuse injuries in sport: A comprehensive overview. J Orthop Surg Res 2018;13(1):309. doi: 10.1186/s13018-018-1017-5

4. Ristolainen L, Kettunen JA, Waller B, Heinonen A, Kujala UM. Training-related risk factors in the etiology of overuse injuries in endurance sports. J Sports Med Phys Fitness 2014;54(1):78-87.

5. Messier SP, Martin DF, Mihalko SL, et al. A 2-year prospective cohort study of overuse running injuries: The runners and injury longitudinal study (TRAILS). Am J Sports Med 2018;46(9):2211-21. doi: 10.1177/0363546518773755.

6. Baarvelda F, Vissera CA, Kollena BJ, Backx FJ. Sports-related injuries in primary health care. Fam Pract 2011;28(1):29-33. doi: 10.1093/fampra/ cmq075.

7. Dakin SG, Newton J, Martinez FO, et al. Chronic inflammation is a feature of Achilles tendinopathy and rupture. Br J Sports Med 2018;52(6):359-67. doi: 10.1136/bjsports-2017-098161.

8. Dean BJ, Gelthings P, Dakin SG, Carr AJ. Are inflammatory cells increased in painful human tendinopathy? A systematic review. $\mathrm{Br}$ J Sports Med 2016;50(4):216-20. doi: 10.1136/ bjsports-2015-09754.

9. Cook JL, Purdam CR. The challenge of managing tendinopathy in competing athletes. $\mathrm{Br} \mathrm{J}$ Sports Med 2014;48(7):506-09. doi: 10.1136/ bjsports-2012-092078.

10. Cook JL, Stasinopoulos D, Brismée JM. Insertional and mid-substance Achilles tendinopathies: Eccentric training is not for everyone - Updated evidence of non-surgical management. J Man Manip Ther 2018;26(3):119-22. doi: 10.1080/10669817.2018.1470302.

11. Cook JL. Ten treatments to avoid in patients with lower limb tendon pain. $\mathrm{Br} J$ Sports Med 2018;52(14):882. doi: 10.1136/ bjsports-2018-099045.

12. Dean BJ, Lostis E, Oakley T, Rombach I, Morrey ME, Carr AJ. The risks and benefits of glucocorticoid treatment for tendinopathy: A systematic review of the effects of local glucocorticoid on tendon. Sem Arthritis Rheum 2014;43(4):570-76. doi: 10.1016/j. semarthrit.2013.08.006.

13. Andriolo L, Altamura SA, Reale D, Candrian C, Zaffagnini F, Filardo G. Nonsurgical treatments of patellar tendinopathy: Multiple injections of platelet-rich plasma are a suitable option. A systematic review and meta-analysis. Am J Sports Med 2019;47(4):1001-18. doi: 10.1177/0363546518759674.

14. Chen $X$, Jones IA, Park C, Vangsness CT Jr. The efficacy of platelet-rich plasma on tendon and ligament healing. A systematic review and meta-analysis with bias assessment. Am J Sports Med 2018;46(8):2020-32. doi: 10.1177/0363546517743746.

15. Fitzpatrick J, Bulsara M, Zheng $\mathrm{MH}$. The effectiveness of platelet-rich plasma in the treatment of tendinopathy. A metaanalysis of randomized controlled clinical trials. Am J Sports Med 2018;45(1):226-33. doi: 10.1177/0363546516643716.

16. Lamplot JD, Rodeo SA, Brophy RH. A practical guide for the current use of biologic therapies in sports medicine. Am J Sports Med 2019:363546519836090. doi: 10.1177/0363546519836090.

17. Pas HIMFL, Moen MH, Haisma HJ, Winters M. No evidence for the use of stem cell therapy for tendon disorders: A systematic review. Br J Sports Med 2017;51(13):996-1002. doi: 10.1136/ bjsports-2016-096794.

18. Johnston CA, Taunton JE, Lloyd-Smith DR, McKenzie DC. Preventing running injuries. Practical approach for family doctors. Can Fam Physician 2003;49:1101-09.

19. Pegrum J, Self A, Hall N. Iliotibial band syndrome. BMJ 2019;364:1980. doi: 10.1136/bmj.1980.

20. Burrus MT, Werner BC, Starman JS, et al. Chronic leg pain in athletes. Am J Sports Med 2014;43(6):1538-47. doi: 10.1177/0363546514545859.

21. Winters $M$. The diagnosis and management of medial tibial stress syndrome. An evidence update. Unfallchirurg 2019. doi: 10.1007/s00113-0190667-z.

22. Blackman P. Shin pain in athletes: Assessment and managment. Aust Fam Physician 2010;39(1-2):24-29.

23. Winters M, Bakker EWP, Moen MH, Barten CC, Teeuwen R, Weir A. Medial tibial stress syndrome can be diagnosed reliably using history and physical examination. Br J Sports Med 2018;52(19):1267-72. doi: 10.1136/ bjsports-2016-097037.

24. Rajasekaran S, Hall MM. Nonoperative management of chronic exertional compartment syndrome: A systematic review. Curr Sports Med Rep 2016;15(3):191-98. doi: 10.1249/ JSR.0000000000000261.

25. Vajapey S, Miller TL. Evaluation, diagnosis, and treatment of chronic exertional compartment syndrome: A review of current literature. Phys Sportsmed 2017;45(4):391-98. doi: 10.1080/00913847.2017.1384289.

26. Diercks R, Bron C, Dorrestijn O, et al. Guideline for diagnosis and treatment of subacromial pain syndrome: A multidisciplinary review by the Dutch Orthopaedic Association. Acta Orthop 2014;85(3):314-22. doi: 10.3109/17453674.2014.920991.

27. Matzkin E, Suslavich K, Wes D. Swimmer's shoulder: Painful shoulder in the competitive swimmer. J Am Acad Orthop Surg 2016;24(8):527-36. doi: 10.5435/JAAOS-D-1500313.

28. Hanchard NC, Lenza M, Handoll HH, Takwoingi Y. Physical tests for shoulder impingements and local lesions of bursa, tendon or labrum that may accompany impingement. Cochrane Database Syst Rev 2013;(4):CD007427. doi: 10.1002/14651858.CD007427.pub2.

29. Hegedus EJ, Goode AP, Cook CE, et al. Which physical examination tests provide clinicians with the most value when examining the shoulder? Update of a systematic review with meta-analysis of individual tests. $\mathrm{Br} J$ Sports Med 2012;46(14):964-78. doi: 10.1136/ bjsports-2012-091066. 
30. Alqunaee M, Galvin R, Fahey T. Diagnostic accuracy of clinical tests for subacromial impingement syndrome: A systematic review and meta-analysis. Arch Phys Med Rehabil 2012;93(2):229-36. doi: 10.1016/j. apmr.2011.08.035.

31. Hermans J, Liume JJ, Meuffels DE, Reijman M, Simel DL, Bierma-Zeinstra SM. Does this patient with shoulder pain have rotator cuff disease? The Rational Clinical Examination systematic review. JAMA 2013;310(8):837-47. doi: 10.1001/ jama.2013.276187.

32. Boudreault J, Desmeules F, Roy JS, Dionne C, Frémont $P$, Macdermid JC. The efficacy of ora non-steroidal anti-inflammatory drugs for rotator cuff tendinopathy: A systematic review and metaanalysis. J Rehabil Med 2014;46(4):294-306. doi: 10.2340/16501977-1800.

33. Steuri R, Sattelmayer M, Elsig S, et al. Effectiveness of conservative interventions including exercise, manual therapy and medical management in adults with shoulder impingement: A systematic review and meta-analysis of RCTs. Br J Sports Med 2017;51(18):1340-47. doi: 10.1136/ bjsports-2016-096515.
34. Cook T, Minns Lowe C, Maybury M, Lewis JS. Are corticosteroid injections more beneficial than anaesthetic injections alone in the management of rotator cuff-related shoulder pain? A systematic review. Br J Sports Med 2018;52(8):497-504. doi: 10.1136/bjsports-2016-097444.

35. Whittle S, Buchbinder R. In the clinic. Rotator cuff disease. Ann Intern Med 2015;162(1):ITC1-15. doi: 10.7326/AITC201501060.

36. Karjalainen TV, Jain NB, Page CM, et al. Subacromial decompression surgery for rotator cuff disease. Cochrane Database Syst Rev 2019;1:CD005619. doi: 10.1002/14651858. CD005619.pub3. 